\title{
Anatomia E Histoquímica das Folhas De Senna alata
}

\author{
Anatomy and Histochemistry of Senna alata Leaves
}

\author{
RODRIGUES, I.M.C. ${ }^{2}$, SOUZA FILHO, A.P.S. ${ }^{3}$, FERREIRA, F.A. ${ }^{4}$, ILKIU-BORGES, F. ${ }^{3}$ e \\ GURGEL, E.S.C. ${ }^{5}$
}

\begin{abstract}
RESUMO - Senna alata é uma espécie daninha frequente em pastagens da região amazônica, cujas folhas apresentam propriedades medicinais. Indivíduos dessa espécie foram cultivados e coletados no Campo Experimental da Embrapa Amazônia Oriental, em Belém-PA, para a realização de análises anatômica e histoquímica das folhas, com a finalidade de fornecer elementos para a taxonomia, identificação microscópica de aleloquímicos e caracterização ecofisiológica da espécie. As folhas apresentaram duas formas de tricomas: tectores e glandulares. Outras características foliares encontradas na espécie foram: lâmina foliar anfiestomática, mesofilo dorsiventral e epiderme abaxial papilosa. Algumas dessas características sugerem um mecanismo de adaptação a ambientes com excesso de calor. As folhas são ricas em cristais de oxalato de cálcio, ao longo de suas nervuras - característica da subfamília Caesalpinioideae. Compostos fenólicos, como flavonoides e antraquinonas, foram encontrados em células epidérmicas, da base de tricomas, e células dispersas no parênquima paliçádico, especialmente nas proximidades da nervura mediana. Este estudo confirmou a presença de conhecidas classes de aleloquímicos em diferentes tipos de células do mesofilo de Senna alata.
\end{abstract}

Palavras-Chave: aleloquímicos, Caesalpinioideae, compostos fenólicos.

\begin{abstract}
Senna alata is one of the most frequent weed species in the Amazonian region pastures. Its leaves present medicinal properties. Individuals of this species were cultivated and collected in the Experimental Field of Embrapa Amazônia Oriental, Belém-PA, to carry out anatomical and histochemical analyses to provide taxonomy information, microscopic identification of allelochemicals and ecophysiological characterization of the species. Leaves presented two forms of trichomes: tector and glandular. Other foliar characteristics of the species were: amphistomatic leaf, dorsiventral mesophyll and abaxial epidermis papillose. Some of these suggest an adaptation mechanism to excessive warm environments. Also, the leaves are rich in calcium oxalate crystals along their veins, a characteristic of Caesalpiniodeae subfamily. Phenolic compounds, such as flavonoids and anthraquinones, were found in epidermal and basal trichome cells, and scattered cells from palisade parenchyma, especially near the midvein. This study confirms the presence of known allelochemical classes in different types of cells in Senna alata mesophyll.
\end{abstract}

Keywords: allelochemicals, Caesalpinioideae, phenolic compounds.

\section{INTRODUÇÃO}

Milhares de compostos bioativos com propriedades inexploradas existem na natureza. Muitos desses metabólitos secundários despertaram o interesse de cientistas em estudar a sua estrutura, biossintese e distribuição, mas não a sua função natural, até que alguns autores apontaram funções importantes desses compostos em plantas e

1 Recebido para publicação em 2.9.2008 e na forma revisada em 15.5.2009.

Parte da dissertação de mestrado da primeira autora.

2 Mestranda do Dep. de Fitotecnia da Universidade Federal de Viçosa - DFT/UFV, 36570-000 Viçosa-MG, Brasil, Bolsista CNPq, <izabellamcr@yahoo.com.br>; ${ }^{3}$ Pesquisador Embrapa Amazônia Oriental, Trav. Enéas Pinheiro, S/N, 66095-100 Belém-PA, Brasil;

${ }^{4}$ Professor do Dep. de Fitotecnia da UFV; ${ }^{5}$ MCT/MPEG/CBO, Caixa Postal 399, 66040-170 Belém-PA. 
ecossistemas. Quando não estão sendo utilizadas, essas substâncias são frequentemente estocadas em vacúolos e espaços intercelulares. Entretanto, podem ser liberadas para a defesa, atração ou como sinais químicos. Desde então, o papel da alelopatia nas funções fisiológicas, bioquímicas e ecológicas tem sido mais esclarecido. Muitos compostos voláteis, como terpenoides, são liberados pelas plantas em áreas secas (Chou, 1999). Em contraste, fitotoxinas hidrofilicas, como fenóis, flavonoides e alcaloides, são liberados pelas plantas em áreas úmidas (Chou, 1999).

Na região amazônica, grande parte das áreas de pastagens cultivadas é infestada por plantas daninhas, sendo esse um grande problema de ordem bioeconômica a limitar o desempenho produtivo. Conhecida popularmente como mata-pasto, Senna alata é um exemplo de espécie prejudicial às pastagens da região. É perene, arbustiva, de crescimento rápido, pertencente à família Leguminosae, subfamília Caesalpinioideae. Nesta subfamília, Senna Mill. está entre os três maiores gêneros, com cerca de 250 espécies (Cronquist, 1981). A espécie é frequente em áreas de pastagens, beira de estradas e terrenos baldios em quase todo o Brasil, sobretudo em lugares úmidos (Lorenzi, 2000). Em inventário florístico realizado em vegetação secundária na região Bragantina, a leste de Belém do Pará, Senna alata foi encontrada entre os indivíduos de Leguminosae - família representada pelo maior número de espécies (Baar et al., 2004).

Possui propriedades terapêuticas, devendo ser ministrada com cautela, pois é suspeita de ser tóxica aos rins e considerada abortiva (Lorenzi, 2000). Já foi demonstrada, também, a atividade antibacteriana, antifúngica e antidermatofitica do extrato de $S$. alata (Ali-Emanuel et al., 2003; Awal et al., 2004; Ordoñez et al., 2004; Pieme et al., 2006). Entre seus componentes até então identificados estão taninos, triterpenos, esteroides, alcaloides, carboidratos redutores, flavonoides, saponinas, cumarinas, antocianidinas, emodina, antraquinona, chrysarabina, ribarina, ácido málico, tartárico, crisofânico e óleo essencial (Ordoñez et al., 2004; Barrese Pérez et al., 2005; PLANTAMED, 2007).

$\mathrm{O}$ fato de uma determinada planta produzir uma substância química com função específica não invalida a possibilidade de essa mesma planta servir como fonte química para outra finalidade. Muitos compostos com comprovadas propriedades medicinais foram investigados quanto aos seus efeitos alelopáticos (SouzaFilho, 2006). Além disso, espécies selvagens exibem maior probabilidade de síntese de metabólitos secundários, devido às pressões seletivas de ambientes adversos e da competição (Souza-Filho \& Alves, 2002). $\mathrm{O}$ estudo realizado anteriormente por Agbagwa et al. (2003) demonstrou os efeitos alelopáticos do extrato bruto de folhas de Senna alata, que induziu um decréscimo consistente no percentual absoluto e na taxa de germinação, além de inibir o crescimento da radícula em Celosia argentea.

Os caracteres anatômicos dos órgãos vegetativos das plantas servem como dados adicionais às características morfológicas externas, podendo ser usados para resolver problemas taxonômicos (Metcalfe \& Chalk, 1950). Em uma planta, a folha é o órgão vegetativo que apresenta maior variação estrutural, e as variações em seus caracteres estruturais têm sido interpretadas como adaptações a condições ambientais. Revela grande valor o exame das epidermes, não só pela forma e grandeza das suas células, mas particularmente pelos outros elementos ali encontrados, de estruturas muito variadas, em particular os estomatos, pelos e glândulas externas (Costa, 1975).

São escassos os estudos de morfologia e anatomia de espécies de Leguminosae, como as descrições apresentadas por Solereder (1908) e Metcalfe \& Chalk (1950), que apresentam características anatomicas de relevância taxonômica nas principais famílias das dicotiledôneas. Embora caracteres anatômicos da família Leguminosae, Caesalpinioideae, tenham sido estudados por alguns outros autores (Carvalho, 1983-1985; Lesten \& Curtis, 1993, 1994, 1996; Francino et al., 2006; Moreira-Coneglian \& Oliveira, 2006; De-Paula \& Oliveira, 2007), as espécies do gênero Senna carecem de estudos anatômicos e histoquímicos.

Pesquisas em alelopatia representam um campo novo da ciência, que deve ser contínuo e expandido por todas as áreas. Dada a grande importância de Senna alata, principalmente 
para a região Norte do Brasil, devido à preferência por lugares úmidos, este trabalho foi realizado com a finalidade de identificação da espécie através do estudo anatômico de suas folhas e obtenção de elementos para a identificação microscópica de aleloquímicos produzidos e/ou estocados nesse órgão vegetal. Uma vez que esse tipo de estudo é raro na área de alelopatia, os resultados dos testes histoquímicos servirão como elemento de localização e identificação da natureza química de aleloquímicos nas células do mesofilo e para a prospecção dos princípios ativos. Além disso, seus dados anatômicos podem auxiliar na caracterização ecofísiológica da espécie, servindo de apoio para a melhor definição desta.

\section{MATERIAL E MÉTODOS}

\section{Coleta do material vegetal}

Senna alata foi plantada no Campo Experimental da Embrapa Amazônia Oriental, localizado na cidade de Belém, Estado do Pará. O plantio ocorreu em fevereiro de 2006. Uma amostra da espécie, identificada por botânicos dessa instituição, foi depositada no herbário sob registro IAN 183561. Em março de 2008, foram coletadas, aleatoriamente, folhas completamente expandidas de dez indivíduos adultos escolhidos ao acaso. Foram coletados folíolos da base, meio e ápice dessas folhas (Figura 1).

\section{Microscopia de luz}

Os folíolos foram divididos em três regiões: apical, mediana e basal, fixados em $\mathrm{FAA}_{50}$ e estocados em etanol 70\% (Johansen, 1940). Posteriormente, foram retirados das amostras fragmentos de aproximadamente $25 \mathrm{~mm}^{2}$, da região da nervura central e margem dos folíolos. Os fragmentos foram desidratados em série etílica e incluídos em metacrilato (Historesin, Leica), seguindo a técnica usual em anatomia vegetal (Johansen, 1940).

Com o auxílio de micrótomo rotativo da marca Leica RM2145, foram confeccionadas as lâminas permanentes. A montagem foi feita em Entelan (Johansen, 1940). Foram realizados, ainda, cortes paradérmicos à mão livre, submersos por algumas horas em hipoclorito de sódio comercial. O material foi corado em seguida com azul de toluidina $\mathrm{pH} 4$, verde malaquita e astrablau (Braga, 1977).

As fotomicrografias foram obtidas com câmera digital acoplada a fotomicroscópio Axioskop MC80, Carl Zeiss.

\section{Microscopia eletrônica de varredura}

Fragmentos de aproximadamente $25 \mathrm{~mm}^{2}$ de folíolos do material em análise foram submetidos ao processo de desidratação em série etanólica (30, 50, 70, 80, 90, 95 e 100\%), por um período total de duas horas e vinte minutos. Posteriormente, as amostras foram

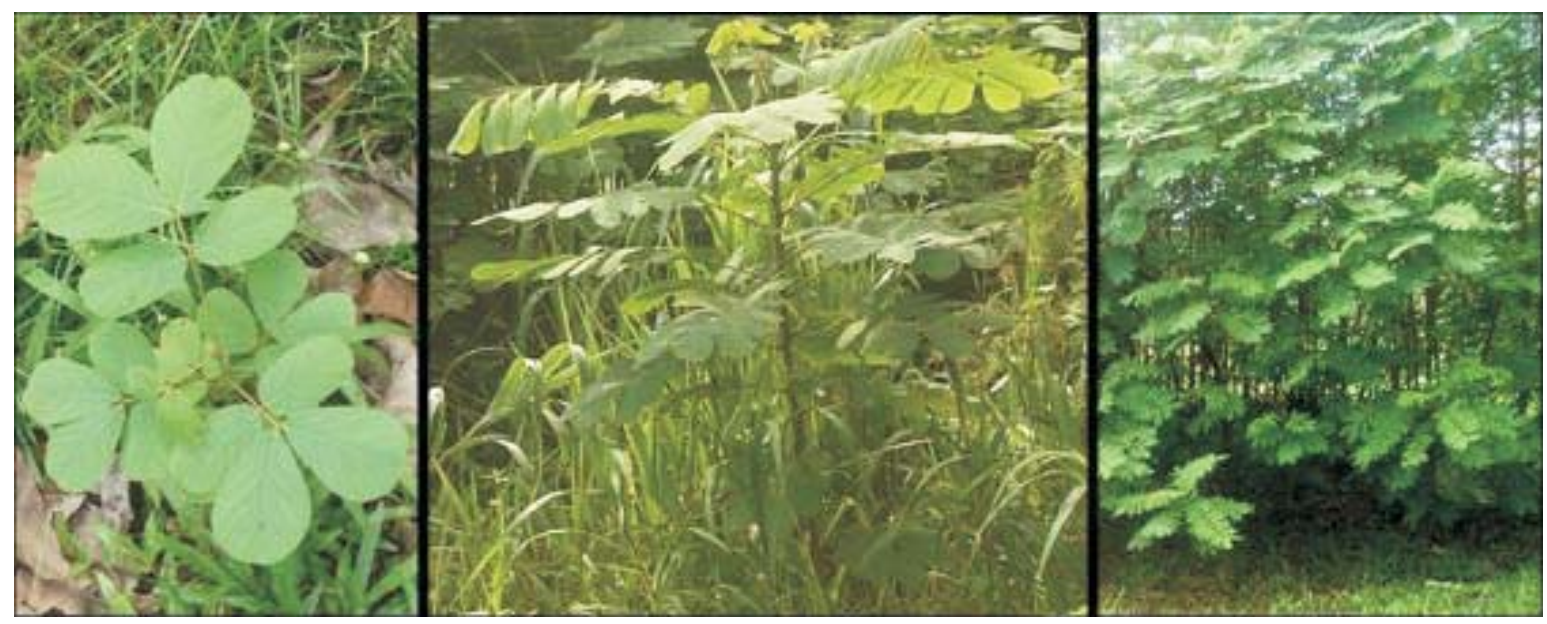

Figura 1 - Senna alata no Campo Experimental da Embrapa Amazônia Oriental, Belém, em diferentes fases de desenvolvimento. 
secas ao ponto crítico, que consiste na substituição do etanol por $\mathrm{CO}_{2}$ líquido (Bozzola \& Russel, 1991), e metalizadas com pó de ouro, a fim de que fossem depositadas, devidamente organizadas, em suportes circulares de metal (stubs), para obtenção de fotos em microscópio eletrônico de varredura (MEV) JMS-5400 LV, JEOL, do Laboratório de Geologia do Museu Paraense Emílio Goeldi, Belém, Pará.

\section{Histoquimica}

Para confecção de lâminas semipermanentes, foram utilizados cortes à mão livre de folhas frescas (região da nervura mediana) feitos com lâminas de aço, com a finalidade de realizar testes histoquímicos.

Os testes aplicados e as respectivas classes de metabólitos avaliadas encontramse resumidos na Tabela 1. Testes histoquímicos foram realizados para identificação de alcaloides, lipídios e compostos fenólicos. A natureza química dos cristais foi analisada pela sua solubilidade em ácido clorídrico.

\section{RESULTADOS E DISCUSSÃO}

\section{Foliolos}

As características das folhas e folíolos citadas para a espécie Senna alata, em levantamento realizado por Rodrigues et al. (2005), foram confirmadas neste trabalho. As folhas apresentam de 7 a 13 pares de folíolos, glândulas ausentes, foliolos obovados ou oblongos, ápice arredondado, obtuso ou retuso, base obliqua, face adaxial glabrescente e abaxial puberulenta.

Os folíolos são anfiestomáticos. O tipo de estômato predominante é o paracítico (Figura 2A, C), com ocorrência de estômatos anisocíticos. Tricomas tectores (Figuras 2, 3 e 4) foram observados sobre ambas as faces da lâmina foliolar. Os tricomas tectores são unisseriados (Figura 3A, E-F), longos com granulação de cera em sua superfície (Figura 3C), mais adensados sob a nervura mediana (Figura 2D e E) na face abaxial. A face adaxial apresenta pelos tectores esparsos (Figura 3F). Foram encontrados pelos glandulares unicelulares esparsos com base espessa, na forma de balão ou clava e geralmente em sulcos
(Figura 4C), sobre a nervura mediana na face abaxial (Figuras 4 e 5A-C). Alguns deles apresentavam-se flácidos e enrugados, provavelmente por terem liberado seu conteúdo, e outros, rompidos (Figuras 4B e 5A-C).

Solereder (1908), Metcalfe \& Chalk (1950) e Watson (1981) comentam que o tipo mais comum de estômato na subfamília Caesalpinioideae é o paracítico, além de mencionar que muitos gêneros, em especial Cassia (Senna), apresentam folhas com estômatos usualmente confinados à superfície inferior, mas algumas vezes descritos também na superior em certas espécies de Cassia (Senna), como foi observado no presente estudo. Segundo Costa (1975), em geral, o indumento de tricomas atinge maior desenvolvimento na face abaxial.

Senna alata é considerada uma planta que apresenta alta taxa de fotossintese e de condutância estomática em nivel foliar (Marabesi, 2007). Folhas anfiestomáticas são comuns em plantas com alta capacidade fotossintética, podendo indicar que essa é uma característica adaptativa em Senna alata, devido à seleção competitiva e às adversidades do meio (Fahn, 1990). Nesse sentido, também, a presença de tricomas pode ser interpretada como proteção de estômatos e até mesmo do mesofilo contra o excesso de calor e, ainda, no isolamento e reflexão da luz (Monteiro et al., 1985). Segundo Metcalfe \& Chalk (1950), pelos não glandulares unicelulares de vários tamanhos e tipos são

Tabela 1 - Testes histoquímicos aplicados para detecção das principais classes de aleloquímicos em folhas de Senna alata

\begin{tabular}{|l|l|l|}
\hline \multicolumn{2}{|c|}{ Grupo metabólico } & \multicolumn{1}{c|}{ Reagente } \\
\hline \multirow{2}{*}{ Lipídios } & \multirow{2}{*}{$\begin{array}{l}\text { Lipídios totais } \\
\text { Compostos } \\
\text { fenólicos }\end{array}$} & $\begin{array}{l}\text { Cudan III, Sudan Black } \\
\text { (Johansen, 1940; Jensen, 1962) }\end{array}$ \\
\hline fenólicos gerais & $\begin{array}{l}\text { Dicromato de potássio } \\
\text { (Gabe, 1968) }\end{array}$ \\
\cline { 3 - 3 } & $\begin{array}{l}\text { Cloreto férrico } \\
\text { (Johansen, 1940; Costa, 1975) }\end{array}$ \\
\cline { 3 - 3 } & Taninos & $\begin{array}{l}\text { Hidróxido de sódio } \\
\text { (Costa, 1975) }\end{array}$ \\
\cline { 3 - 4 } & $\begin{array}{l}\text { Sulfato ferroso } \\
\text { (Johansen, 1940) }\end{array}$ \\
\hline Alcaloides & $\begin{array}{l}\text { Reagente de Dragendorff } \\
\text { (Costa, 1975) }\end{array}$ \\
\hline Cristais de oxalato de cálcio & $\begin{array}{l}\text { Ácido clorídrico } \\
\text { (Chamberlain, 1932) }\end{array}$ \\
\hline
\end{tabular}




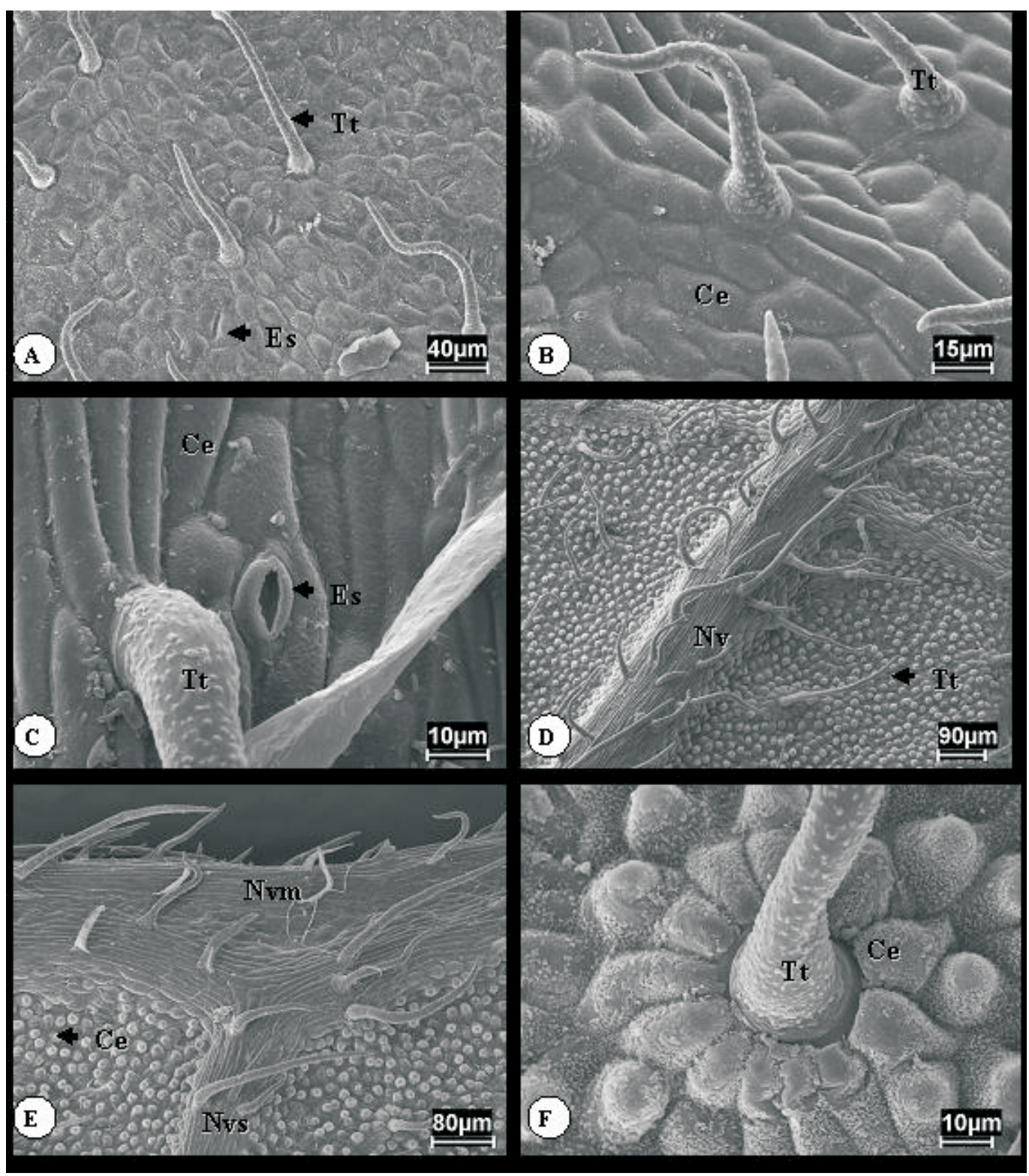

Figura 2 - Epidermes de Senna alata em microscopia eletrônica de varredura; A - face adaxial com tricomas e estômatos; B - epiderme da face adaxial; $\mathbf{C}$ - nervura mediana, face abaxial com tricoma e estômato; $\mathbf{D}$ e $\mathbf{E}$ - face abaxial, epiderme papilosa e tricomas sobre nervuras; $\mathbf{F}$ - células epidérmicas dispostas radialmente na base do tricoma, face abaxial. Abreviaturas - Ce: células epidérmicas, Es: estômato, Nv: nervura, Nvm: nervura mediana, Nvs: nervura secundária, Tt: tricoma tector.

encontrados no gênero Cassia (Senna); em Cassia armata, constitui-se fino e longo, superficialmente granulado, e curvado em C. obtusa. Metcalfe \& Chalk (1950) citam também a presença de tricomas glandulares hirsutos com base esférica em certas espécies de Cassia (Senna), ou largo em forma de clava, visivel a olho nu, ocorrendo na margem de folhas de $C$. occidentalis.

\section{Epiderme}

A epiderme é unisseriada em ambas as faces dos folíolos, papilosa na face abaxial (Figuras 2D-F e 3A-D ) e não papilosa ou subpapilosa na face adaxial (Figuras 2A-B e 3F). As células epidérmicas apresentam ainda, em sua superficie, deposição de cera em forma de pequenas placas (Figura 3B-D). Em vista 
frontal, as paredes anticlinais das células epidérmicas são sinuosas (Figura 5E). As células da base dos tricomas são dispostas radialmente (Figuras $2 \mathrm{D}-\mathrm{F}$ e $3 \mathrm{~A}-\mathrm{C}$ ).

Metcalfe \& Chalk (1950) assinalam a ocorrência de epiderme papilosa e subpapilosa em algumas espécies de Cassia (Senna). Funções similares às dos tricomas têm sido atribuídas à epiderme papilosa, como proteção aos estômatos ou incremento da reflexão dos raios solares (Monteiro et al., 1985).

\section{Mesofilo}

Secções transversais da lâmina foliar revelam mesofilo com organização dorsiventral (Figuras 4A e 5D), que foi encontrado no

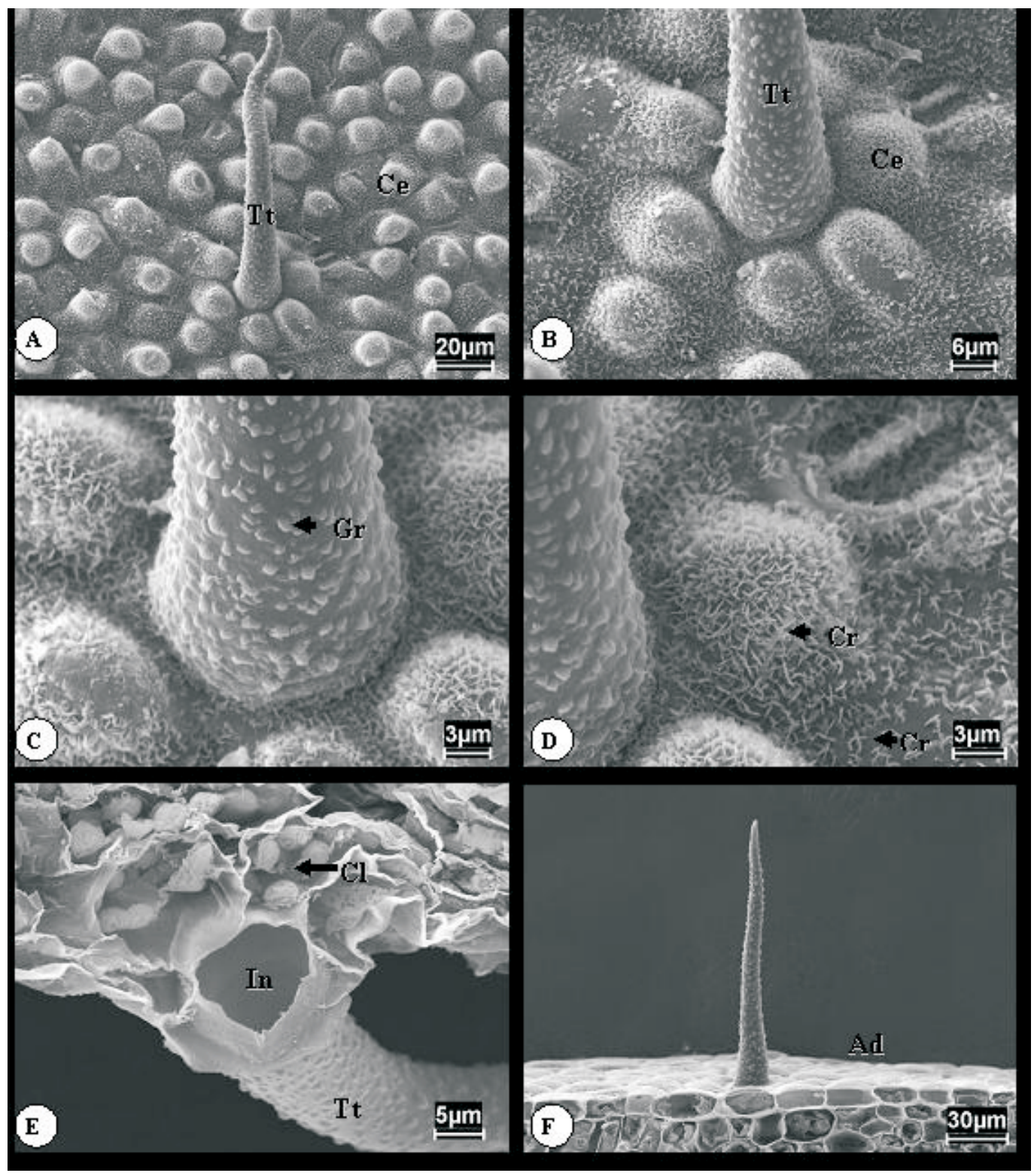

Figura 3 - Epidermes de Senna alata em microscopia eletrônica de varredura. A e B - face abaxial com tricomas e epiderme papilosa; $\mathbf{C}$ - tricoma tector com granulações de cera em sua superfície; D - deposições de cera em forma de placa sobre a epiderme abaxial; $\mathbf{E}$ - detalhe de um corte transversal, mostrando tricoma tector unisseriado aberto na face abaxial e células subepidérmicas com cloroplastos; F - detalhe de um corte transversal, mostrando células epidérmicas e subepidérmicas da face adaxial. Abreviaturas -Ad: face adaxial, Ce: células epidérmicas, Cl: cloroplastos, Cr: cera, Gr: granulações, In: interior, Tt: tricoma tector. 
gênero Cassia (Senna) por Metcalfe \& Chalk (1950). O parênquima paliçádico é voltado para a face adaxial do foliolo e apresenta predominantemente um estrato de células curtas, podendo, às vezes, apresentar dois estratos (Figura 5D). O parênquima lacunoso apresenta-se compacto, devido ao tamanho pouco desenvolvido das lacunas; suas células têm formas variadas e pouco ramificadas.

Diferentemente dos resultados obtidos para Senna alata, Costa (1975) afirma que as folhas do sene ( $S$. angustifolia) não possuem dorsiventralidade e apresentam um tipo de mesofilo cêntrico heterogêneo, com tecido lacunoso entre as camadas de paliçada.

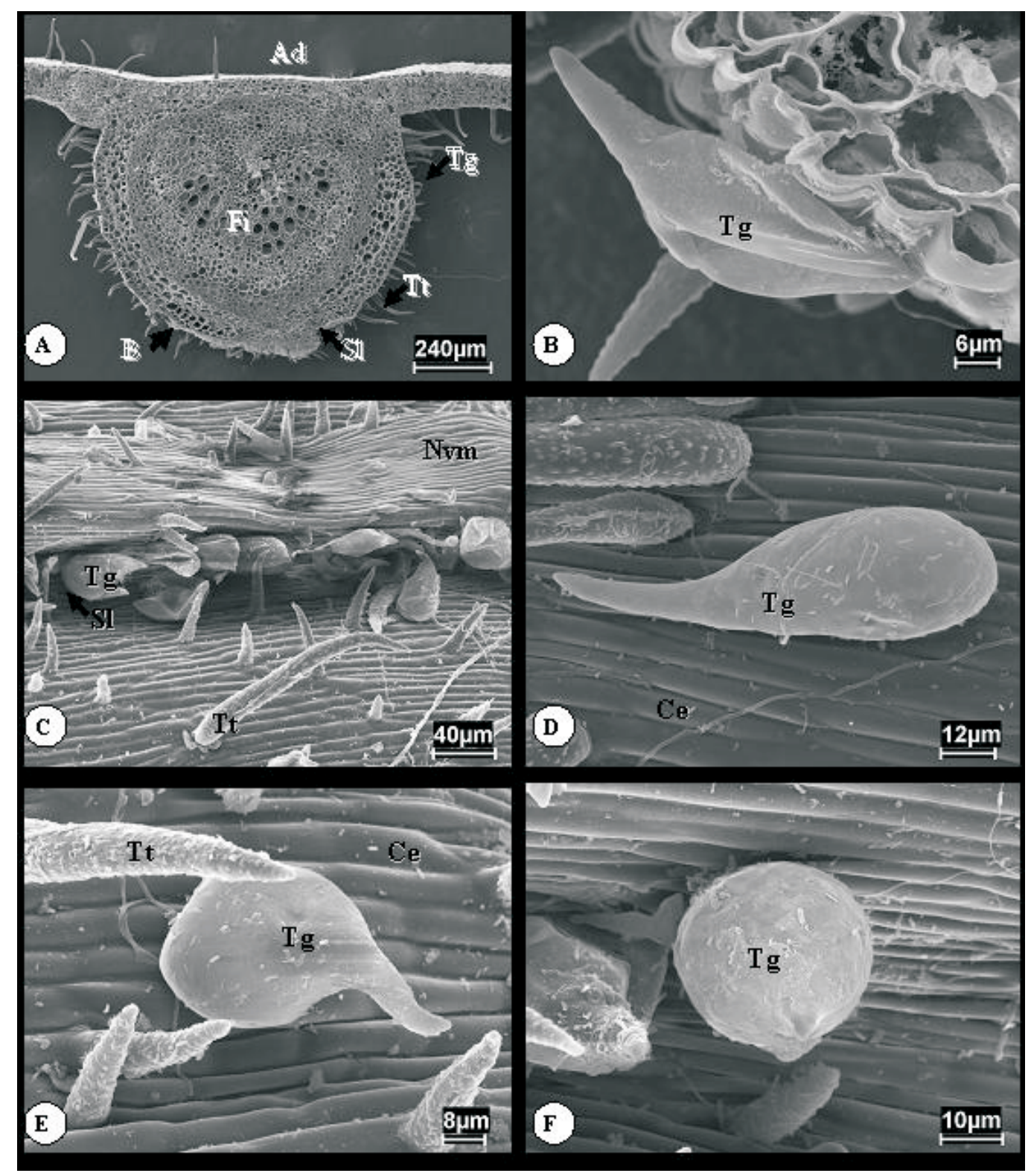

Figura 4 - Folhas de Senna alata em microscopia eletrônica de varredura. A - corte transversal na região da nervura mediana; B detalhe do corte transversal A, mostrando tricoma glandular sobre nervura mediana, face abaxial; $\mathbf{C}$ - tricomas glandulares dispostos em sulco sobre a nervura mediana, face abaxial; D, E e F - tricomas glandulares sobre epiderme da nervura mediana, face abaxial. Abreviaturas - Ad: face adaxial, Ce: células epidérmicas, Fi: fibras, Sl: sulco, Nvm: nervura mediana, Tg: tricoma glandular, Tt: tricoma tector. 


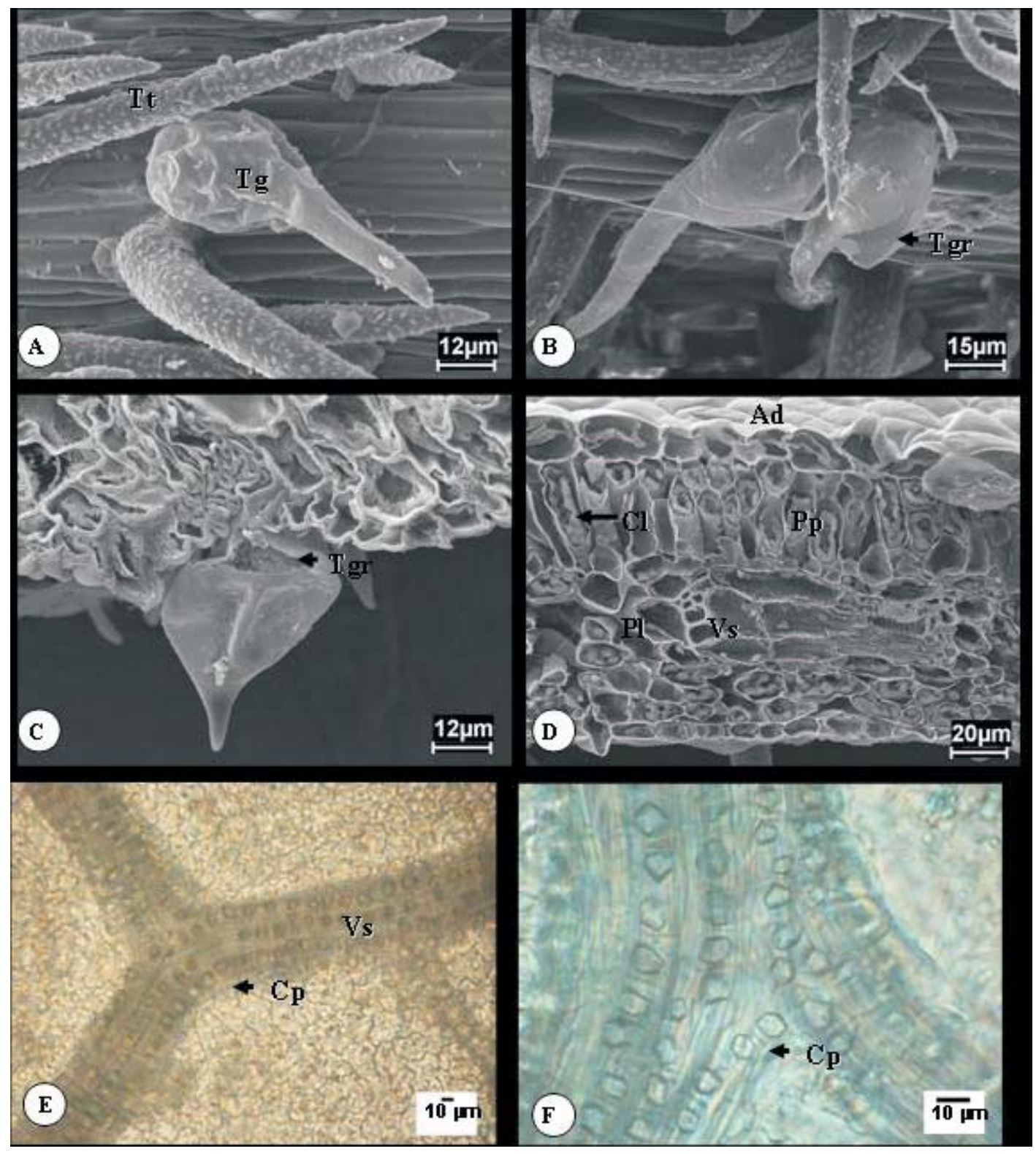

Figura 5 - Folhas de Senna alata em microscopia eletrônica de varredura e microscopia de luz. A - tricoma glandular flácido sobre epiderme da nervura mediana, face abaxial; $\mathbf{B}$ - tricoma glandular rompido sobre epiderme da nervura mediana, face abaxial; $\mathbf{C}$ tricoma glandular rompido sobre epiderme da face abaxial; D - detalhe de um corte transversal de mesofilo; $\mathbf{E}$ e F - vista frontal do limbo foliar em corte paradérmico, feixes vasculares apresentando cristais prismáticos agrupados. Abreviaturas - Ad: face adaxial, Cl: cloroplastos, $\mathbf{C p}$ : cristais prismáticos, Fi: fibras, PI: parênquima lacunoso, Pp: parênquima paliçádico, Tg: tricoma glandular, Tgr: tricoma glandular rompido, Tt: tricoma tector, Vs: feixes vasculares.

\section{Vascularização}

Os feixes são do tipo colateral; fibras ocorrem associadas aos feixes (Figura 4A), mas a natureza dessas fibras deve ser posteriormente analisada. Metcalfe \& Chalk (1950) comentam que feixes vasculares das nervuras são usualmente acompanhados por esclerênquima, enterrados no mesofilo em espécies de Cassia (Senna).

As células epidérmicas, na região da nervura, são alongadas (Figuras $2 \mathrm{C}-\mathrm{E}, 4 \mathrm{C}-\mathrm{F}$ e 5A-B). Foram observados, na face abaxial ao 
longo da nervura mediana, sulcos onde se adensavam tricomas glandulares (Figura 4C). A nervura mediana é proeminente na face abaxial (Figuras 2D-E e 4A). O mesofilo, nas proximidades da nervura mediana, não apresenta suas células diferenciadas em paliçádico e lacunoso (Figura 4A); na face adaxial e na face abaxial tem-se o parênquima propriamente dito.

Cristais prismáticos de oxalato de cálcio foram encontrados acompanhando as nervuras foliares (Figura 5E-F). Metcalfe \& Chalk (1950) afirmaram que a presença de grupos de cristais, especialmente no mesofilo, é um caráter utilizado para diferenciação entre as subfamílias de Leguminosae. No estudo anatômico foliar de Cassia ensiformes também foi evidenciada a presença desses cristais (Carvalho, 1983-1985).

\section{Histoquímica}

A reação para detecção de lipídios totais evidenciou a presença desses compostos na cutícula e nas paredes espessas das fibras associadas aos feixes (Tabela 2).

Após a reação com hidróxido de sódio, foram observadas nos cortes transversais algumas células epidérmicas na face abaxial, na região da nervura mediana, coradas de castanho-avermelhado. Também se coraram algumas células dispersas pelo mesofilo, com maior concentração nas proximidades das nervuras, na altura de ambas as epidermes e, algumas vezes, associadas às células da base dos tricomas (Tabela 2). Imediatamente após o contato dos cortes com a solução de hidróxido de sódio, observou-se que as células da região da nervura mediana coraram-se de castanho-avermelhado. O hidróxido de sódio $5 \%$, segundo Costa (1975), já referido como agente esclarecedor na montagem das preparações microscópicas, é também um reagente cromático: com os compostos antraquinônicos, cora-se de vermelho, dissolve a hesperidina e cora-se de amarelo; com os taninos e alguns outros compostos fenólicos, origina cor castanha, que escurece com o passar do tempo.

Algumas células da base de tricomas, na região da nervura mediana, e células do parênquima paliçádico coraram-se de castanho após a reação com cloreto férrico (Tabela 2). Segundo Costa (1975), solução aquosa de cloreto férrico $1 \%$ em contato com taninos produz colorações verde-enegrecidas (outros compostos com hidróxidos fenólicos produzem também colorações).

À semelhança da reação ocorrida com hidróxido de sódio e cloreto férrico, após reação com dicromato de potássio, células do parênquima paliçádico e da epiderme abaxial na região da nervura mediana coraram-se de castanho (Tabela 2).

Para reconhecimento dos metabólitos nas células utilizam-se habitualmente reagentes corantes - alguns específicos, outros mais gerais. Assim, algumas vezes recomenda-se o emprego simultâneo de mais de uma reação cromática (Costa, 1975). Devido à presença de compostos fenólicos pertencentes a classes distintas, nas folhas de Senna alata, foram realizados três testes histoquímicos diferentes para detecção desses compostos.

As reações para detecção de taninos e alcaloides não revelaram a presença desses compostos (Tabela 2) no material analisado.

Tabela 2 - Resultados dos testes histoquímicos

\begin{tabular}{|l|l|c|l|}
\hline \multicolumn{2}{|c|}{ Grupo metabólico } & Resultado & \multicolumn{1}{c|}{ Local encontrado } \\
\hline Lipídios & Lipídios totais & + & Cutícula e paredes espessas de fibras associadas aos feixes \\
\hline \multirow{2}{*}{$\begin{array}{l}\text { Compostos } \\
\text { fenólicos }\end{array}$} & $\begin{array}{l}\text { Compostos } \\
\text { fenólicos gerais }\end{array}$ & Taninos & $\begin{array}{l}\text { Células epidérmicas, células dispersas no mesofilo, parênquima } \\
\text { paliçádico e células da base de tricomas, na região da nervura } \\
\text { mediana }\end{array}$ \\
\cline { 2 - 4 } & - & Ao longo das nervuras \\
\hline Alcaloides & - & + & - \\
\hline Cristais de oxalato de cálcio & &
\end{tabular}

+ (presença); -(ausência). 
O gênero Senna é pródigo como fonte de compostos de natureza antraquinônica, com diversas propriedades biológicas e farmacológicas (Alemayehu et al., 1998). Em testes fitoquímicos anteriores, realizados com indivíduos de Senna alata provenientes do mesmo local de coleta deste trabalho, foram identificadas, em suas folhas, as classes quimicas: ácidos graxos, alcaloides e compostos fenólicos, como antraquinonas, cumarinas, flavonoides, saponinas e taninos (Rodrigues et al., 2009). Dessa forma, os testes histoquímicos selecionados para a realização do presente trabalho foram referentes a essas classes.

Os flavonoides, de acordo com Costa (1975), encontram-se localizados, habitualmente, nos tecidos superficiais, nas células epidérmicas, nas camadas em paliçada, nos parênquimas esponjosos, dissolvidos no suco celular sob a forma de heterosídios; quando o conteúdo atinge um valor elevado, aparecem sob a forma de cristais ou de massas coradas de amarelo. Solubilizam-se nos hidróxidos alcalinos e resultam em soluções mais intensamente coradas de amarelo-alaranjado ou escurecido.

Já os compostos antraquinônicos encontram-se dissolvidos no citoplasma das células parenquimatosas e conferem a estas a sua cor amarela ou avermelhada característica (Costa, 1975). Na face abaxial das folhas mais maduras de Senna alata são observadas, a olho $\mathrm{nu}$, algumas manchas avermelhadas sob a nervura mediana.

Metcalfe \& Chalk (1950) assinalam a presença de pelos glandulares, células secretoras de vários tipos e até nectários em Caesalpinioideae e com variados conteúdos; contudo, de acordo com Solereder (1908), os idioblastos taniníferos, comuns nas Papilionoideae, são raros em Caesalpinioideae.

Os sistemas de defesa das plantas são considerados complexos e, nos representantes das subfamílias Caesalpinioideae e Mimosoideae (Leguminosae), estão, algumas vezes, relacionados à produção de taninos e terpenoides, além de interações simbióticas com formigas, por exemplo (Polhill et al., 1981). Na África, Senna alata é plantada ao redor das casas, para espantar formigas (Barrese Pérez et al., 2005).

As folhas apresentaram duas formas de tricomas: tectores e glandulares. Também foram descritas outras características foliares para a espécie, como lâmina foliar anfiestomática, mesofilo dorsiventral, epiderme abaxial papilosa e deposição de cera sobre as células epidérmicas. Algumas dessas características sugerem um mecanismo de adaptação a ambientes com excesso de calor, favorecendo a reflexão da luz e proteção dos estômatos. As folhas são ricas em cristais de oxalato de cálcio ao longo de suas nervuras, característica da subfamília Caesalpinioideae, assim como estômatos predominantemente paracíticos. Compostos fenólicos, como flavonoides e antraquinonas, foram encontrados em células epidérmicas, da base de tricomas e células dispersas no parênquima paliçádico, especialmente nas proximidades da nervura mediana.

Este estudo fornece características anatômicas foliares específicas de Senna alata, que, juntamente de outros caracteres mais gerais, permitem sua identificação por meio da análise microscópica dessa estrutura. A presença de tricomas glandulares em forma de clava, ao longo de sulcos sobre a nervura mediana de seus folíolos, e de tricomas tectores longos, adensados na face abaxial, com granulações de cera em sua superficie, são algumas das características específicas. Além disso, confirmou-se a presença de conhecidas classes de aleloquímicos em diferentes tipos de células do mesofilo de $S$. alata. As colorações foram discretas e efêmeras nos testes histoquímicos; dessa forma, não se pode inferir com exatidão a origem de biossintese dos compostos encontrados para a indicação na prospecção destes, devendo ser realizados mais testes para essa conclusão, especialmente com as células dos tricomas glandulares.

\section{AGRADECIMENTOS}

Os autores agradecem ao CNPq, pela bolsa concedida, ao Laboratório de Geologia e Anatomia Vegetal do Museu Paraense Emílio Goeldi e ao Laboratório de Agroindústria da Embrapa Amazônia Oriental, Belém, Pará, pelos equipamentos utilizados. A Tarcymara B. Garcia e Rolf Júnior Ferreira da Silva, pelo auxílio técnico. Ao Departamento de Fitotecnia da Universidade Federal de Viçosa, pela estrutura fornecida. Agradecimento especial à Dayana Maria Teodoro Francino, do Departamento de Botânica da UFV, pela valiosa ajuda. 


\section{LITERATURA CITADA}

AGBAGWA, I. O.; ONOFEGHARA, F. A.; MENSAH, S. I. Stimulation of growth and development of Celosia argentea L. by crude extracts of Senna alata (L.) Roxb. J. Appl. Sci. Environ. Manag., v. 7, n. 1, p. 9-13, 2003.

ALEMAYEHU, G.; ABEGAZ, B.; KRAUS W. A. 1-4, anthraquinone-dihydroantrhacenone dimer from Senna sophera. Phytochemistry, v. 48, n. 4, p. 699-702, 1998.

ALI-EMANUEL, N. et al. Treatment of bovine dermatophilosis with Senna alata, Lantana camara anad Mitracarpus scaber leaf extracts. J. Ethnopharmacol., v. 86, p. 167-171, 2003.

AWAL, M. A. et al. Brine shrimp toxicity of leaf and seed extracts of Cassia alata Linn. and their antibacterial potency. J. Med. Sci., v. 4, n. 3, p. 188-193, 2004.

BAAR, R. et al. Floristic inventory of secondary vegetation in agricultural systems of East-Amazonia. Biodiver.

Conserv., v. 13, n. 3, p. 501-528, 2004

BARRESE PÉREZ, Y; HERNÁNDEZ JIMÉNEZ, M. E. PULPEIRO, O. G. Caracterización y estudio fitoquímico de Cassia alata L. R. Cub. Plant. Med., v. 10, n. 2, p. 1-5, 2005.

BOZZOLA, J. J.; RUSSEL, L. D. Electron microscopy. Boston: Jones and Bartlett Publishers, 1991. 542 p.

BRAGA, M. M. N. Anatomia foliar de Bromeliaceae da Campina. Acta Amaz., v. 7, n. 1, p. 1-74, 1977.

CARVALHO, D. M. G. Anatomia foliar de Cassia ensiformis Vell. (Leguminosae - Caesalpinioideae). Arq. JBRJ, v. 27, p. $157-169,1983-1985$

CHAMBERLAIN, C. J. Methods in plant histology. 5.ed. Chicago: University of Chicago, 1932. p. 86.

CHOU, C. H. Roles of allelopathy in plant biodiversity and sustainable agriculture. Crit. Rev. Plant Sci., v. 18, n. 5, p. 609-636, 1999.

COSTA, A. F. Farmacognosia. 3.ed. Lisboa: Fundação Calouste Gulbenkian, 1975. v. 1. 1031 p.

CRONQUIST, A. An integrated system of classification of flowering plants. New York: Coloumbia University Press, $1981.1262 \mathrm{p}$.

DE-PAULA, O. C.; OLIVEIRA, D. M. T. Variação da estrutura carpelar em seis espécies de Cassiinae (Leguminosae: Caesalpinioideae). Acta Bot. Bras., v. 21, n. 4, p. 915-925, 2007.
FAHN, A. Plant anatomy. 4.ed. Oxford: Pergamon Press, 1990. $588 \mathrm{p}$.

FRANCINO, D. M. T. et al. Anatomia foliar e caulinar de Chamaecrista trichopoda (Caesalpinioideae) e histoquímica do nectário extrafloral. Planta Daninha, v. 24, n. 4, p. $695-705,2006$.

GABE, M. Techniques histologiques. Paris: Masson e Cie, 1968. $1113 \mathrm{p}$.

JENSEN, W. A. Botanical histochemistry: principles and pratice. San Francisco: W. H. Freeman \& Co, 1962. 408 p.

JOHANSEN, D. A. Plant microtechnique. New York: McGraw- Hill, 1940. 523 p.

LERSTEN, N. R.; CURTIS, J. D. Subepidermal idioblasts in leaets of Caesalpinia pulcherrima and Parkinsonia aculeata (Leguminosae; Caesalpinioideae). B. Torrey Botanic. Club, v. 120 , p. $319-326,1993$

LERSTEN, N. R.; CURTIS, J. D. Leaf anatomy in Caesalpinia and Hoffmannseggia (Leguminosae, Caesalpinioideae) with emphasis on secretory structures Plant Syst. Evol., v. 192, p. 231-255, 1994.

LERSTEN, N. R.; CURTIS, J. D. Survey of leaf anatomy, especially secretory structures, of Tribe Caesalpinieae (Leguminosae; Caesalpinioideae). Plant Syst. Evol., v. 200, n. $1-2$, p. $21-39,1996$

LORENZI, H. Plantas daninhas do Brasil: terrestres, aquáticas, parasitas, tóxicas e medicinais. 3.ed. Nova Odessa: Plantarum, 2000. $608 \mathrm{p}$

MARABESI, M. A. Efeito do alto $\mathbf{C O}_{2}$ no crescimento inicial e na fisiologia da fotossíntese em plântulas Senna alata (L.) Roxb. 2007. 78 f. Tese (Mestrado em Biodiversidade Vegetal e Meio Ambiente) - Instituto de Botânica da Secretaria do Meio Ambiente, São Paulo, 2007.

METCALFE, C. F.; CHALK, L. Anatomy of the

Dicotyledons: Leaves, stem and wood in relation to taxonomy with notes on economic uses. Oxford: Clarendon Press, 1950. v. 1.724 p.

MONTEIRO, W. R.; CASTRO, M. M.; GIULIETTI, A. M. Aspects of leaf structure of some species of Leiotrix Ruhl. (Eriocaulaceae) from Serra do Cipó (Minas Gerais, Brazil) R. Bras. Bot., v. 7, n. 1, p. 137-147, 1985.

MOREIRA-CONEGLIAN, I. R.; OLIVEIRA, D. M. T. Anatomia comparada dos limbos cotiledonares e eofilares de dez espécies de Caesalpinioideae (Fabaceae). R. Bras. Bot., v. 29, n. 2 , p. $193-207,2006$

ORDOÑEZ, M. G.; GOVÍN, E. S.; LOS BLANCO, M. A. G Actividad antimicrobiana de Senna alata L. R. Cub. Plant. Med., v. 9, n. 1, p. 0-0, 2004 
PIEME, C. A. et al. Evaluation af acute and subacute toxicities of aqueous ethanolic extract of leaves of Senna alata (L.) Roxb (Caesalpiniaceae). Afric. J. Biotechnol., v. 5, n. 3, p. 283-289, 2006.

\section{PLANTAMED - Plantas e ervas medicinais e} fitoterápicos Disponível em: <http://

www.plantamed.com.br/plantaservas/especies/

Senna_alata.htm $>$ Acesso em: 30 abr. 2007

POLHILL, R. M.; RAVEN, P. H.; STIRTON, C. H. Evolution and systematics of the leguminosae. In: POLHILL, R.M.; RAVEN, P.H. (Eds.) Advances in legume systematics. Kew: Royal Botanic Gardens, 1981. Part 1. p. $1-26$

RODRIGUES, I. M. C.; SOUZA FILHO, A. P. S.; FERREIRA, F. A. Estudo fitoquímico de Senna alata. por duas metodologias. Planta Daninha, v. 27, n. 3, p. 507-513, 2009 .
RODRIGUES, R. S. et al. O gênero Senna (Leguminosae, Caesalpinioideae) no Rio Grande do Sul, Brasil. Acta Bot. Bras., v. 19, n. 1, p. 1-16, 2005.

SOLEREDER, H. Systematic anatomy of the

dicotyledons. Oxford: Clarendon Press, 1908. v. 2. 1182 p.

SOUZA FILHO, A. P. S.; ALVES, S. M. Alelopatia princípios básicos e aspectos gerais. Belém: Embrapa Amazônia Oriental, 2002. 260 p

SOUZA-FILHO, A. P. S. Alelopatia e as plantas. Belém: Embrapa Amazônia Oriental, 2006. 159 p.

WATSON, L. An automated system of generic description for Caesalpinioideae, and its application to classification and key-making. In: POHILL, R. M.; RAVEN, P. H. (Eds.) Advances in legume systematics. Kew: Royal Botanic Gardens, 1981. Part 1. p. 65-80. 